\title{
Seminar for Master's Thesis Projects: Promoting Students' Self-Regulation
}

\author{
Shirley Miedijensky ${ }^{1} \&$ Einat Lichtinger ${ }^{1}$ \\ ${ }^{1}$ Oranim Academic College of Education, Tivon, Israel \\ Correspondence: Shirley Miedijensky, Oranim Academic College of Education, Tivon, Israel. E-mail: \\ Shirley_m@oranim.ac.il \\ Received: August 11, 2016 \\ Accepted: August 31, 2016 \\ Online Published: September 9, 2016 \\ doi:10.5430/ijhe.v5n4p13 \\ URL: http://dx.doi.org/10.5430/ijhe.v5n4p13
}

\begin{abstract}
This study presents a thesis seminar model aimed at promoting students' self-regulation. Students' perceptions regarding the contribution of the seminar to their learning process were characterized and the seminar's effect upon their self-regulation expressions was examined. Data was collected using questionnaires and analyzed thematically. The most significant components of the seminar, according to the students, were cognitive knowledge and guidance regarding thesis writing, along with peer learning, and changes in self-efficacy and ability to regulate time and emotion. Students demonstrated self-regulating mechanisms for planning, setting goals, monitoring, self-encouragement, and emotion control. The results emphasize the significance of self-regulation in thesis-writing.
\end{abstract}

Keywords: Thesis, Thesis seminar, Self-regulation, Academic writing, Motivation

\section{Introduction}

Literature dealing with thesis writing generally focuses on the academic writing itself (e.g., Aitchison, 2009; Delyser, 2003; Phillips, 2012) or on supervisory aspects (Guerin, Kerr \& Green, 2015; Nordentoft, Thomsen \& Wichmann-Hansen, 2013; Sullivan \& Ogloff, 1998). Very few studies describe and characterize seminars that support thesis writing or promote self-regulation (SR) processes. This study focuses on a model thesis-writing seminar given during master's programs at an academic college for education. The seminar focused on promoting SR processes, which can enhance the students' ability and motivation to cope with the challenge of writing (Graham \& Harris, 2000). In particular, SR can increase students' autonomy and responsibility for their work, and the uniqueness of this course was its aim to foster in students the ability to deal independently with the cognitive, emotional, and social challenges inherent in thesis writing. As such, it gave students the opportunity to learn how to regulate their own learning.

The objectives of the present study were twofold: a) to characterize students' perceptions regarding the contribution of the seminar to their learning process and b) to examine students' SR expressions throughout the seminar's duration.

\section{Theoretical Framework}

\subsection{Seminars for Theses and Dissertations}

In most universities, students are required to take at least one "thesis seminar" course and sometimes several, during which they present their research topic, theoretical framework, and chosen methodology, and, if already available, preliminary findings (Greer \& Ross, 2013). Only a few studies have investigated the importance of thesis seminars, the teaching and learning processes involved, or the ability of thesis advisors to advance the student in an academic sense (Semeijn, Semeijn \& Geldeman, 2009). Delyser (2003), for example, developed a unique thesis seminar for graduate students of geography that focused on writing skills, critical reading of academic papers, presenting the different stages of research, peer learning, and critiques. Ferguson (2009) also developed a unique thesis writing group that focused on the writing process, critiquing, reflexivity, structure, and style.

In developing a thesis seminar for postgraduate teachers, one must consider that the majority of students are adults, whose expectations are different than those of younger students: for most, their choice of studies comes from a desire for change in their professional and/or personal lives. Despite having less academic experience, they bring with them professional and life experience. Lecturers in academia should allow for this, and the courses should provide 
appropriate tools to help students fulfill their roles as learners and succeed in their studies (Fejes, Johansson, \& Dahlgren, 2005; Merrill, 2001).

Graduate-level academic writing skills require processing information using techniques of comparison and analysis and then integrating that information into a cohesive text. Many graduate students have difficulty writing to proper academic standards (Aitchison \& Guerin, 2014; Lillis \&Turner, 2001; Phillips, 2012; Ylijoki, 2001), and instructors often express a sense of discontent regarding their students' skills in this area, noting paucity of language, difficulty in creating coherent structures, and unfamiliarity with writing conventions. Crucial concepts - the formal structure of an academic manuscript, academic style, citation methods, and correct semantics, to name a few - are not clear to students.

One way to overcome these difficulties is through a peer-learning format. Allowing students to discuss their writing experiences during the seminar develops their ability to constructively criticize others' work (Greer \& Ross, 2013).

\subsection{Self-assessment, Peer Feedback, Self-regulation}

The seminar model in this study is based on self- and peer-assessment processes. Self-assessment requires learners to rank their own performance and learning (Topping, 2003) and to define for themselves what "good" work in a given situation is, leading students to actively take responsibility for their own learning (Shepard, 2000). With peer assessment, students learn to evaluate the level and quality of their peers' performance and output based on clear criteria presented by the instructor beforehand (Struyven, Dochy \& Janssens, 2003). Peer feedback can promote action and reflection, turning the students' experiences into accessible knowledge as they discuss the rationale behind their own and their colleagues' decisions (Falchikov \& Goldfinch, 2000).

Nicol and Macfarlane-Dick (2006) claim that self-assessment and peer feedback can develop student SR processes and list the following seven advantages that SR, self-assessment, and peer feedback practices provide:

- clarifying the definition of "good" performance (goals, criteria, expected standards);

- facilitating the development of self-assessment (reflection) in learning;

- delivering high quality information to students about their learning;

- encouraging teacher and peer dialogue regarding learning;

- encouraging positive motivational beliefs and self-esteem;

- providing opportunities to close the gap between current and desired performance;

- providing information to teachers to help shape teaching.

SR is an active process of self-management. Zimmerman's (2000) three-phase SR model comprises planning, performance control, and self-reflection. Planning set the goals for action. Performance control occurs during learning and affects motivation and action. In the final, self-reflection phase, learners mentally review their performance and determine whether there is a need for changes in behavior or strategies.

These three processes encompass the contexts that the individual is trying to regulate: cognition, motivation, emotion, and behavior - all within their physical and social environments (Pintrich, 2000). Numerous studies over the past decades ( e.g., Boekaerts \& Corno, 2005; Schunk \& Ertmer, 2000; Schunk \& Zimmerman, 2007a) have addressed the issue of identifying SR processes and the correlation between them, motivation, and academic success. The studies focused on characterizing general and specific SR processes, and identifying cognitive strategies, meta-cognitive strategies (setting goals, planning, monitoring, and self-testing), motivational strategies (self-encouragement and self-award), and resource-regulation (attention, social environments, and scheduling) that allow students to direct their learning and achieve their academic goals (Garcia \& Pintrich, 1994; Zimmerman, 2002, 2008).

Zimmerman (2002) suggests a social-cognitive view in which SR is a process connecting the self with environmental events and behaviors. He claims that SR behavior is influenced by the sense of self-efficacy and social influences. In addition, students who interact with other learners are more likely to practice self-reflection, which drives goal-oriented behavior (Henderson \& Cunningham, 1994).

Most SR models assume that the students' motivation greatly influences their success in SR (Schunk \& Zimmerman, 2007b). Students' beliefs regarding self-efficacy, learning expectations, and the value of the undertaking influence their willingness to activate self-regulating processes and ultimately have a bearing on their success (Zimmerman, 2008). In other words, the more a learner is active strategically, the greater the chances of his eventual success, which creates a feeling of self-efficacy and an increase in motivation (Schunk \& Ertmer, 2000). 
It is difficult to track the development of SR processes since they are internal; they are a result of interaction with the environment and not a result of direct guidance. Studies that wish to assess such processes must thus be sensitive to the complexity of the situation and any interpersonal interactions involved (Corno, 1995), since SR is influenced by interactions with teachers and peers, by the student's level of familiarity with the structure and concepts of the content studied, and by the student's feeling of her level of capability to cope with the task. In order to handle this complexity, researchers have utilized information from the instructors, who described the impact of environmental cues on their students' SR development (Boekaerts \& Cascallar, 2006).

Bembenutty (2007) emphasized the positive correlation between SR and teacher-students' feelings of self-efficacy, success in setting goals, and passion for their profession. He claimed that programs designed for in-service teachers must enhance students' SR skills by strengthening their abilities to set goals, develop strategies, monitor their progress, develop positive beliefs, and reflect upon their achievements. According to Schunk and Pajares' model (2005), SR is an important part of teachers' professional development, beginning within their social framework, where they acquire academic skills, and developing through such internal sources as setting personal standards, self-encouragement, and self-efficacy. The teacher is perceived as an agent involved in his own development. He affects his surroundings and is, in turn, affected by them. Because the teacher's knowledge, rules, strategies, and beliefs are influenced by observing his peers, self-regulation processes are essential to his professional development (Sanz de Acedo Lizarraga et. al., 2009).

\section{Method}

The study was carried out during three applied-thesis seminars offered in the second year of MEd studies. Each seminar comprised four sessions of five hours each (total 20 hours); one-on-one sessions with students took place over the semester as required.

\subsection{Seminar for Applied Thesis}

The seminar was developed in the context of our work as lecturers in the graduate studies program in the college. We created an outline of the core elements in writing a research proposal and then worked out the components for each element, thus constructing the framework of the seminar to be given under the guidance of two instructors.

The seminar framework was based on the contextual paradigm to learning and teaching, which aims to enhance students' SR strategies. Authentic learning was made possible by focusing on student interests, and the seminar included a number of elements geared to individual students plus work in peer groups. The syllabus was flexible, so that content could be altered to match students' progress, as the primary goal was to significantly advance the preparation of the thesis proposal progress. In order to achieve this goal, the following action principles were emphasized:

1. to encourage students to use SR throughout the writing of their research proposals and theses;

2. to review the foundations of academic writing and promote writing strategies;

3. to familiarize students with the structure of a research proposal;

4. to observe the students' research methodology and provide formative assessment; and

5. to create a peer support group.

The seminar comprised four monthly five-hour sessions. Prior to each meeting (including the first one), students were asked to prepare a structured assignment designed to advance the writing of their proposal. The assignment also aimed to promote their ability to self-regulate their progress. Continuous contact with the students was maintained between sessions: by email, through the course website, or, if required, personal meetings.

Each session covered a specific component of the writing process with follow-up assessment as follows: The lesson began with a lecture on the topic. Then students were divided into two groups, each with one instructor, and activities were carried out under the instructor's supervision, with feedback given from both peers and instructor. At the end of each session, goals were defined and set for the next one, each student defined his own individual goals, and students were requested to fill out a reflective questionnaire, which enhanced their self-assessment and allowed the instructors to adjust the content of the next session according to the students' needs. The questionnaire's open-ended questions asked for the most important things learned, what had interested them, their feelings and thoughts on the session, and any requests or suggestions. The instructors conducted a post-session meeting to reflect on the lesson and define issues that needed improving and elements that should to be continued. 
The seminar comprised three main stages (see Figure 1):

The exposure stage. In the first session, characteristics of the extensive thesis and structure of the research proposal were explained. The need for coherency between topic, purpose, and research questions was emphasized. The students, collaborating in small groups under the guidance of the instructor, were asked to present the topic of their paper and formulate their goals. Their peers provided constructive feedback regarding coherence.

Action stage. The next two sessions comprised the "action" stage. The first dealt with setting up the proposal's structure and writing its theoretical background, and the lecture presented aspects of academic writing, writing strategies, and criteria for good writing in general (content, structure, communication, style, grammar, and syntax). During the group exercise, students presented their outline of their literature review along with a number of written paragraphs for the purpose of analyzing writing quality. Feedback (peer and instructor) was meant to help clarify their ideas regarding their writing and to promote their future ability for self-assessment.

The second session was devoted to methodology - approach to research, the research environment, characteristics and description of study participants, research tools, and methods - and relevant ethical issues.

Summary stage. In the fourth (final) session, the focus was on emphasizing how self-regulation skills can be used during research and writing. The first activity involved a round of "final questions" (students had been asked to prepare at least one question that remained unanswered for them). The second activity was a self-regulation one, with an emphasis on the SR processes required for writing a paper, particularly those regarding planning, data gathering, writing self-encouragement statements, and constructing a timetable. The strategies include regulating motivation, time planning, regulating emotions, and dealing with conflicting situations. Finally, students were asked to fill in a perception questionnaire.
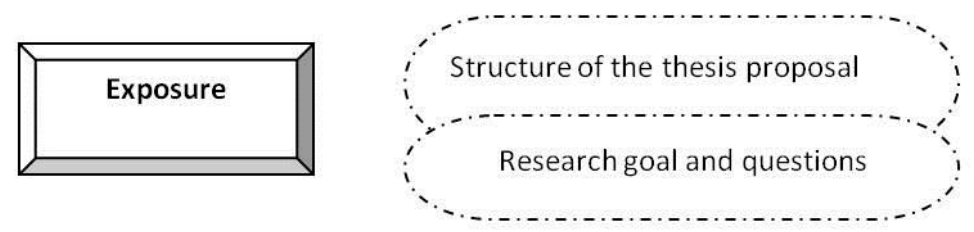

- Lectures

- Peer learning
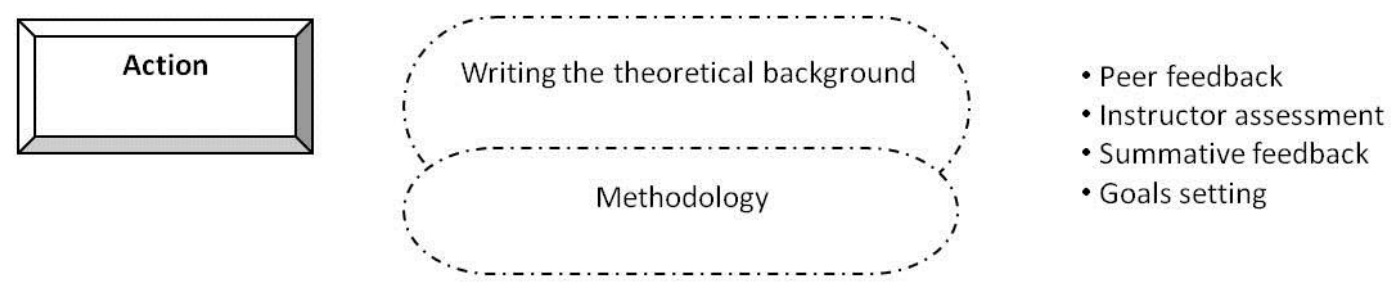

- Peer feedback

- Instructor assessment

- Summative feedback

- Goals setting
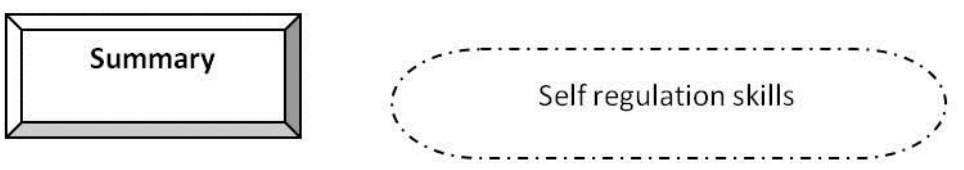

- "Final question"

- Self-regulation activity

Performances and assessment components

Figure 1. The seminar framework

\subsection{Participants}

The participants $(\mathrm{N}=46)$ were postgraduate students in a number of the college's programs: leadership in education, teaching science, student counseling, teaching languages, multidisciplinary teaching, and teaching youth at risk. 


\subsection{Data Collection and Analysis}

This study was qualitative in nature. Data was gathered using two open-ended questionnaires: a reflective questionnaire (RQ) (see Appendix 1) and a perception questionnaire (PQ) (see Appendix 2). The RQ was distributed at the end of each session. It queried the fundamental topics taught each session and invited student feedback: questions that interested the students, emotional aspects, thoughts, requests, and recommendations. The PQ was distributed at the end of the seminar. Students were asked to compare their situations vis-à-vis the preparation of their proposal, student-advisor relationship, emotional states, and feelings of self-efficacy before and after the seminar; they were also asked to add anything they felt worth mentioning.

Thematic analysis as offered by Braun and Clark (2006) was used to analyze the PQ. Student responses were coded, collated, and grouped into themes. We conducted a further analysis to identify SR expressions within student statements. This last analysis and the RQ analysis were based on the SR cyclical model (Zimmerman, 2000) and on Pintrich's (2000) theoretical framework for classifying different processes in SR.

SR components identified included planning and setting goals, monitoring, strategy, self-encouragement, emotional regulation, time control, social regulation, and assessment. These components were quantified and the frequencies of their expression in the three stages of the seminar were calculated, thus allowing a picture of the distribution of the SR components throughout the seminar.

In order to establish credibility in the study's findings, each researcher coded the categories independently, and these were then compared. The inter-rater agreement was $97 \%$ with a kappa value of $0.92(p<0.000)$, which is considered a substantial agreement level between two raters according to the Landis-Koch benchmark scale (Gwet, 2012).

\section{Findings}

\subsection{Contribution of the Seminar according to the Students' Perceptions}

Student responses were classified into two major themes: (1) factors that aided learning during the seminar, and (2) changes that occurred as a result of their participation in the seminar. Each theme included specific categories.

4.1.1 Factors that aided learning during the seminar. The main factors mentioned by the students were knowledge and guidance obtained regarding writing their papers, working in peer groups, SR guidance, and emotional support from instructors. A few noted the importance of required preparations and modeling by instructors (in total 80 statements).

a) Knowledge and guidance regarding thesis writing.

The highest proportion of statements (38\%) concerned proposal writing. Students indicated that the seminar clarified the essence and structure of the proposal and how it should be written, as can be seen in the following examples: "The seminar helped me to understand the requirements and purpose of the proposal, things that were not clear to me at the beginning." "It helped organize my proposal writing and the work involved. I learned on what to focus."

Other statements concerned learning how to write a theoretical review, and, more importantly, how to construct that review logically. "I learned to write a literature review that was focused and adhered to the accepted academic style." "The chapter-headings outline helped me to focus when I began to write the review."

Students also indicated the value of the assistance received in targeting research questions and focusing on methodology and relevant research design: "I found it very interesting to observe the thought processes regarding the topic and how it could be divided into research questions." "The research method and question formulation became much clearer, as did the research tools."

b) Working in peer groups.

The importance of working with peers comprised $23 \%$ of the total statements. As one student stated, "Peer learning enriched my experience even though our research topics were in completely different fields." Specifically, students indicated that working in small groups provided them with feedback from peers as well as the instructor. Discussing their research in groups gave them additional considerations regarding their topic: "Working in groups allowed me to raise questions, hear others' questions, and get answers." "Both the students and the instructors... made me change some aspects of my thinking, which inspired me with new ideas and encouraged me." "Presenting my work to the group was very empowering and taught me a lot." One of the students, however, pointed out that she had difficulty accepting criticism from her peers, despite seeing the benefits: "It's kind of hard to get criticism. But I understood that it was for my own good." 
Other statements regarding peer groups concerned the emotional and motivational reinforcement and empowerment that working in a group afforded, since they saw that they all were in similar situations and coping with similar difficulties regarding writing and keeping to a schedule: "There was a feeling that we were all in the same boat and so it wasn't so bad"; "Emotionally, it was good to hear about everyone's progress and share mine with them"; "In fact, I saw that, compared to the others, my situation wasn't that bad."

c) SR guidance.

Twenty percent of the statements reflected contributions that the seminar made to SR: "I received guidance and learned to self-regulate and to manage myself and my feelings." Students referred to two major areas of SR: planning and emotional regulation.

Planning includes setting goals, making a work plan, and keeping to a timetable. The students noted that making a plan and a working schedule helped them to prepare their proposal: "[They helped me] make a work plan, and decide on its essential components and expected progress." "I learned to set up a timetable to prepare myself for the project."

Students reported that building a timetable motivated and emotionally reinforced them and cited the importance of regulating their emotions: "Writing out the work plan gave me confidence and made me breathe easier. I feel that this is an important step in the process." "I learned to stop every so often to encourage myself, and give myself compliments and reinforcement."

d) Emotional support from instructors.

Students mentioned the personal, caring attention they felt they had received from the instructor in $15 \%$ of the statements. "There's a feeling of support. Someone is listening, advising, and lighting the way." "The emotional support helped to calm my fears and encouraged me to progress in my proposal writing. It gave me the push and motivation to proceed."

e) Pre-session preparations.

A small number of statements (4\%) mentioned the benefit obtained from preparing the assignments before each session. It is apparent that this was mainly helpful to those students who were in the initial stages of their proposal, as the assignments required them to formulate their thoughts: "The seminar forced me to prepare my assignments and stick to the schedule, and thus I was able to formulate my ideas, topic, and research questions."

f) Modeling by instructors.

One student mentioned that the instructors provided a model to help her progress in her work: "I learned by observing you. Your constructive and rational approach inspired me to act similarly to reach my goals."

4.1.2 Changes as a result of participation in the seminar. A substantial number of statements $(n=90)$ applied to changes as a result of the seminar, specifically improvements in emotional state and motivation level, progress in the proposal writing, advisor relationship, self-regulation of the proposal-writing process, and knowledge regarding research and writing processes in general.

a) Changes in emotional state and motivation.

Thirty eight percent of the statements were associated with changes in students' emotional state and level of motivation. Students described their emotional state before the seminar as being distressed and full of misgivings, with feelings of incompetence and anxiety as a result of the difficulty they had in commencing their writing. Added to this was the academic workload that also hindered progression in their thesis writing: "My emotional state was not very good. ... I felt guilty that I wasn't progressing with my proposal." "I had many concerns and didn't believe in my abilities. I felt stressed and overworked and didn't know where to start."

Students also presented misgivings regarding their decision to write a thesis instead of a seminar paper (which was an easier task). As one student wrote: "My emotions were in a turmoil. This is an extended project that requires a huge investment in time and effort, and I, being a working woman, housewife, and mother ... was afraid I'd fail completely."

Students noted a considerable improvement regarding their motivation and increased feelings of self-efficacy after the seminar: "I feel motivated and eager to continue; to progress quickly to its completion." "I have faith in my ability to complete this assignment even ahead of schedule." 
Students noted that improvements in SR processes led to changes in their feelings of self-efficacy since they now had a clear focus on their work: "Today I am more organized and I have tools." "I am glad that my ideas are more focused and I know exactly what steps I need to take."

Others wrote that as a result of their emotional improvement, they were now able to cope with and take responsibility for the writing process: "I feel responsible and involved." "[I] picked myself up and continued working."

b) Progress in writing the proposal.

Students mentioned considerable progress in writing their proposal as a result of the seminar. Over a quarter of the students (27\%) reported that they had not even begun writing their proposal prior to the seminar and had had only a general idea of their topic: "I began the seminar with only a topic. I hadn't developed my ideas, and I had many doubts." Many stated that they had had no idea how to approach the task and had felt confused and lacked understanding: "[Before, ] my perception regarding the requirements was wrong."

Students' statements regarding their situation at the end of the seminar showed that a quarter of them had already finished writing their proposal or were in the final stages thereof: "Before the seminar I only had defined my topic and had barely any research questions. [Now] I have submitted my proposal on time."

Other students were progressing and described their position in the writing process: "At this point I've collected and read material, and I am now ready to sit down and write my proposal." "I have the format and framework sorted out for the writing process." "I have collected my theoretical material and am now reading it and marking ideas relevant to my project."

c) Improvement in the student-advisor relationship.

As mentioned, besides the instructors that accompanied the applied seminar discussed herein, each student had a personal thesis advisor to accompany them throughout the writing process. Data analysis revealed that $14 \%$ of the statements referred to the contribution that the seminar made to the student-advisor relationship. Students reported that they had found it difficult to have ongoing contact with their advisors before the seminar. Reasons included lack of motivation, heavy academic workloads, or uncomfortable feelings regarding the advisor for some personal reasons. For example, they wrote: "[The advisor] was unable to schedule meetings because of his full timetable." After the seminar, students reported that their relationship with their advisor had strengthened and they were now working together: "I went back to speaking more frequently with my advisor because of the many comments and suggestions that I received in the seminar." "[After the seminar] I was more persistent and pressed him [to make time for me]. This was valuable." They also expressed that they now understood the importance of regular meetings with their advisors: "I understand now that scheduling regular appointments (in my journal) with my advisor encourages me to progress. This gives me a clear view of my progress and ensures that we don't lose contact." "The seminar made me understand that I had no option but to adapt myself to him. We are now back in contact."

One student wrote that he was still having difficulty forming a satisfactory relationship with his advisor, but admitted the importance of solving this problem: "We disconnected. I hope that that is temporary and it will work itself out at the end. [Now, after the seminar, I plan] to contact my advisor to expedite matters."

d) Improved SR in writing the proposal.

Students mentioned (11\% of the statements) an improvement in their SR skills when organizing themselves for the process of writing. Specifically, students pointed out an improvement in their ability to plan, manage their time, and regulate their emotions. They described how organizational abilities contribute to a good outlook: "[The seminar] contributed to my ability to cope with stress and a heavy workload." "[The seminar] helped me to manage my time and myself properly." "When I get stuck, I will hang up the yellow page [an organizational page that was prepared in the seminar] on the wall in my workroom and follow it."

e) Improved knowledge regarding the research and writing processes.

Another change that the students mentioned (9\% of statements) was in their knowledge of research and writing. In particular, students noted that they learned how to focus and improve their investigative thinking: "The seminar helped me focus on the research topic and the literature review." "The seminar taught me how to organize the structure of my work properly." "I understand methodology better, and I learned how to check the reliability of a questionnaire." 


\subsection{Expressions of $S R$}

We analyzed the RQs and the final PQs and compiled a list of phrases that indicated SR processes during the seminar. In total, we identified 241 expressions relevant to SR. These were broken down into eight themes: planning and goal setting, monitoring, strategies, self-encouragement, regulation of emotion, time regulation, social regulation, and assessment. The themes were examined for frequency of occurrence during each stage of the seminar: the exposure stage, which included formulating the topic and research questions $(n=27)$; the action stage, which included the structure of the literature review $(n=64)$ and methodology $(n=70)$; and the summary stage, which focused on self-regulation skills $(\mathrm{n}=80)$ (see Figure 2).

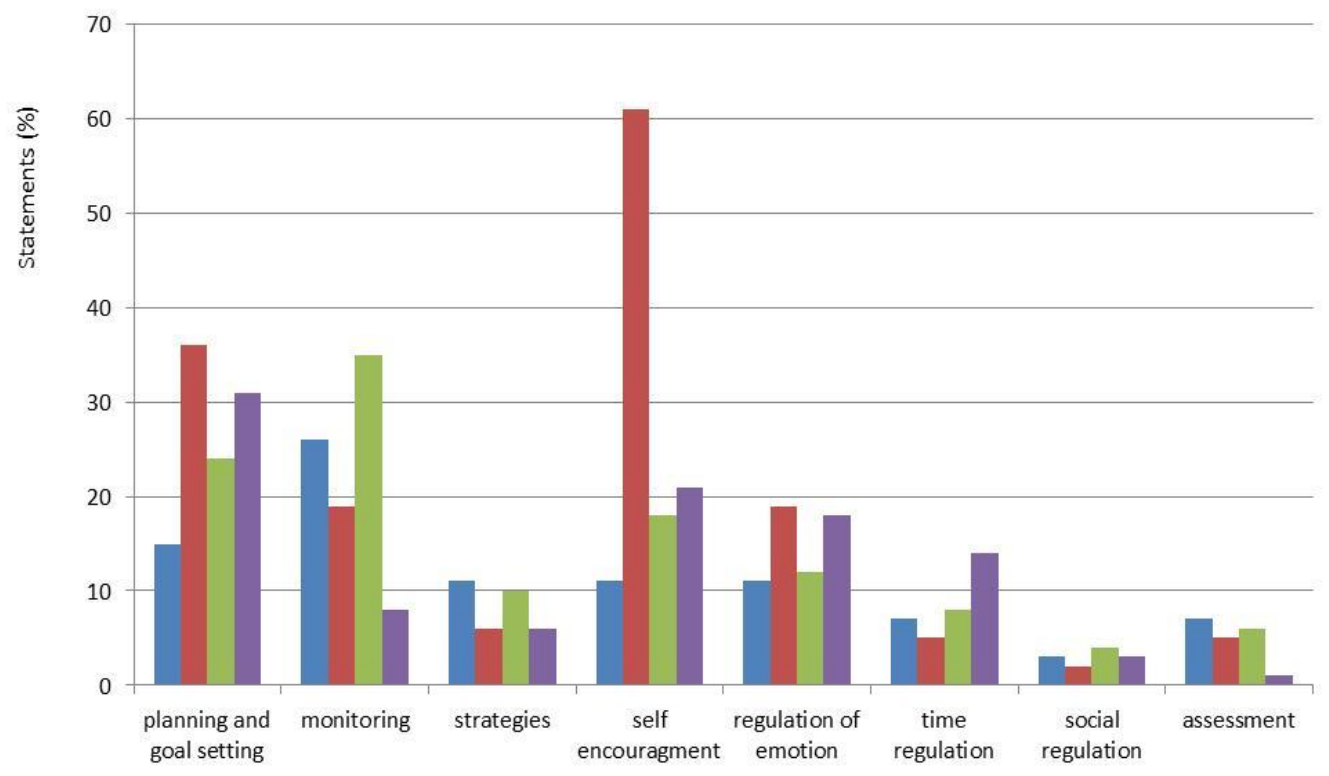

- Thesis subject and the research questions $\quad$ Theoretical background Methodology $\quad$ Summary stage

Figure 2. Distribution of SR statements according to seminar stage

Figure 2 illustrates that the most prevalent SR expressions concern self-encouragement, planning and goal setting, and monitoring, with the former two especially noticeable during the literature review stage. During the methodology stage, monitoring skills were most evident.

Below we examine each stage of the seminar with respect to the various SR components as illustrated by student statements.

The exposure stage had the fewest SR statements, of which "monitoring" provided the most statements $(26 \%)$. Examples of monitoring statements: "I have set up my topic, material and chapter headings, and even have my timetable for the next month and a half." "I had some questions regarding the research population and the research method." "The academic year is about to end and I have not managed to start my research."

During the first part of the action stage (theoretical background), when the focus was on literature review, SR statements were primarily concerned with self-encouragement $(61 \%)$, and planning and goal setting (36\%). Some examples: "I feel very confident, optimistic and motivated to carry on, despite difficulties and fear" (self-encouragement). "Now I need to think how to plan my time so that I will be ready for the next meeting" (goal setting).

Statements showing emotional control (19\%) and self-monitoring (19\%) were also identified. Apparently, the instruction offered during the seminar helped calm students and encouraged them to examine their progress and output: "I feel stressed, but at the same time, I know I will manage" (regulation of emotion); "The table of contents of my literature review is focused and organized at the moment" (monitoring).

During the action phase that addressed methodology, the majority of statements related to monitoring (35\%) or planning and goal setting (24\%). Students were aware that they must meet the demands of the seminar on time in 
order to progress, and therefore must remain focused: "I must keep up to the rate of the seminar and make sure I am accurate and focused." In addition, students came to realize that asking for help from their personal advisors and initiating meetings were their responsibilities: "I understood that I shouldn't give up and must ask my advisor for help and initiate meetings." Also: "I realized some things that need correcting in my proposal and I'm eager (I'm not being cynical!) to go and correct them."

In the summary stage, the prominent statements concerned planning and goal setting (31\%), self-encouragement $(21 \%)$ and regulation of emotion (18\%). The students were aware of their difficulties, but nevertheless expressed belief in their ability to progress and reach their designated targets. They encouraged themselves by focusing on the positive and not overwhelming themselves with negative feelings: "I believe in myself. I know myself. Like any process in my life, at first it is hard to get into it, but when it happens, "the sky is the limit"" (self-encouragement). "The most important thing now is to organized my research framework and begin writing. I intend to finish successfully and with distinction" (planning and goal setting).

A further SR skill that was clearly exhibited in the final stage of the seminar was time management: "I mustn't procrastinate. I must create a timetable for myself, and then I can see that it will be possible."

It is clear, therefore, that throughout the course of the seminar, students exhibited SR skills. At each stage, different SR processes were apparent, but in general, self-encouragement, planning and setting goals, and monitoring were the main ones exhibited.

\section{Discussion}

The results suggest that according to the students, one of the main contributions of the seminar was the overall guidance and knowledge they acquired concerning writing the proposal and thesis. Students indicated improved academic writing skills, and that they had learned to write a literature review in a focused, coherent way. The question arises, of course, about the necessity of having to teach students in post-graduate studies - who should already have the academic writing experience and knowledge required - how to write a thesis. However, as Bansel (2011) claims, "the processes of knowledge production and subject formation are complex, messy and not-always rational" (p. 554). Apparently, the complexity of the writing process (Hidi \& Boscolo, 2006) and the cognitive and emotional burdens of thesis writing require further mediation that concentrates on the specific components of the paper. The structured guidance delivered in the seminar enables students to apply writing strategies, focus on writing sections of their thesis (Delyser, 2003; Phillips, 2012) and regulate their progress while being engaged in the writing process and its end (Graham \& Harris, 2000).

Another noticeable contribution for the students was the significant experience of working in groups that included peer feedback and formative assessment. Students stated that the peer setting provided a sort of emotional support group and encouraged their self-regulation and their progress. Receiving feedback this way gave them the opportunity to ask for clarification, think differently, discuss issues from various perspectives, and eventually reflect on their own research. The group was emotionally calming because it made them realize that everyone was "in the same boat" and to feel that they were not alone. These results indicate the significance of the group setting, especially in a thesis seminar. Our model enabled a comfortable, flexible learning environment that was not threatening to the students. They knew that the instructors and their colleagues were there to support them. Because we co-taught, we were able to provide a model on how to conduct peer feedback that contributes to a supportive learning environment. Our findings are supported by other researchers (Aitchison \& Guerin, 2014; Ferguson, 2009), who found that group learning is very important in postgraduate studies when it included feedback on the thesis.

The findings suggest that there is no separation between emotional and pedagogical aspects while one is in the process of writing one's thesis. Researchers (e.g., Beard, Clegg \& Smith, 2007) claim that one of the possible reasons that there is so little research about the emotional aspects of students' experience in writing a thesis is probably due to the concern of focusing on the psychological aspect rather than the pedagogic one.

The students reported substantial changes in their situation as a result of the seminar. Many indicated an improvement in their emotional state and in their feelings of self-efficacy, and noted that they had made clear progress in the writing of their papers. Most stated that even though they had been feeling distressed and confused, or had been experiencing feelings of "being stuck" at the beginning of the seminar, by its end, they had made significant progress in the writing of their proposal and were now motivated to complete it. Our seminar succeed in creating a supportive learning environment and enhance the feeling of "one for all, and all for one." Such a learning environment can reduce negative emotions, reduce feelings of isolation, bolster confidence, and enable students to effectively regulate themselves and progress in their writing (Ferguson, 2009; Zimmerman \& Schunk, 2008). 
Our results show that the seminar motivated students to initiate contact and strengthen ties with their personal advisors. There is no doubt that awareness of the complexity of the advisor-student relationship is critical to maintaining a healthy rapport (Sullivan \& Ogloff, 1998). Advisors have an important part in motivating and guiding the writing, and therefore consistent, continuous contact with them is crucial cognitively and emotionally (Drennan \& Clarke, 2009; Guerin, Kerr \& Green, 2015).

We also examined indications of SR during the seminar and found that the self-monitoring skills increase in the session that addressed methodology, and that goals-placement and time-management skills were evident in the last session, in anticipation of independent work. Assessment processes were not apparent, probably because the students were still at the active stage of their projects. However, some of them assessed the work that they had done since the commencement of the seminar, which allowed them to better plan future work.

It was clear that in the second stage, which dealt with the literature review, students exhibited more self-encouragement processes, which are vital at such a complex and challenging stage. Self-encouragement is vital to promoting the learning process; without it, there is less value to cognitive SR processes. For example, implementing a monitoring process when the student is inattentive motivationally, can lead to only partial success, if any (Zimmerman \& Schunk, 2008).

Regulating motivation was significantly apparent over the course of the seminar. It was observed that students wrote themselves statements of encouragement, or promised themselves a reward at the completion of some task. These mechanisms increased the students' extrinsic motivation for the task (Wolters, 1998). Motivational regulation is especially valuable during the process of writing a thesis, as such complex writing places emotional and cognitive demands on the writer that can lead to feelings of anxiety and despair (Bruning \& Horn, 2000; Graham \& Harris 2000). Evidence of such problematic feelings is demonstrated in the way students described their feelings before the seminar, and it seems that the motivational regulation process that they activated over the course of the seminar contributed to improvements in their feelings and motivation, as testified at the end of the course.

According to the RQs and the final PQs, statements indicating emotional SR were given in the action and summary stages, but less than expected, considering the statements made by the students regarding the emotional changes they felt during the seminar. It is possible that the scarcity of emotional regulation statements is due to the fact that these are more introverted processes (Eisenberg \& Spinrad, 2004) that students are less inclined to express in writing. However, emotional regulation processes have a strong influence on the progress and social adjustment of students (Park, Edmondson \& Lee, 2012) and on the characteristics of the social environment (Peterson, 2012), so this aspect should be afforded more consideration in future research.

As mentioned, the findings demonstrate that peer work and a cooperative environment contribute to the emotional and motivational welfare of the students, something that is crucial for the drive required for postgraduate studies (Pintrich, 2004). However, because students worked independently on their personal proposals, there was no exhibition of collaborative regulation (co-regulation), nor was their much requirement for processes of social regulation in the group environment. Regarding their concern for the social setting, this was more in the context of each one's personal environment, such as family or personal advisor. Nevertheless, regulating this aspect has been found to be significant for individual progress in writing assignments (Zimmerman, 2002).

In order to effect proper co-regulation processes while writing the paper, we believe there is a need for a more intensive framework, such as a long-term weekly seminar where students can conduct ongoing collaborative learning that would allow forming SR skills as a group, even if group members are on different levels (Volet, Summer \& Thurman, 2009).

Our findings show that over the course of the seminar, students used both cognitive and emotional regulation processes. Research over the years has created a conceptual distinction between cognitive self-regulation procedures, and emotional and social regulation processes (Bodrova \& Leong, 2007). However, in recent years, researchers have realized the need to avoid a dichotomy between them, emphasizing the importance of research to study the link between cognitive and emotional processes and their contribution to one another (Lieberman, Giesbrecht \& Muller, 2007). We believe that a follow-up study is required to specifically examine the connection between the self-regulation processes that various students apply during the seminar and the effects they felt as a result of it.

In conclusion, this study shows the importance of creating a supportive learning community of postgraduate students and designing a course that encourages self-regulation processes and addresses the essential components required for writing their final paper, including cognitive, social, and emotional aspects. We believe that further studies can probe deeper into the regulation processes and personal strategies that students use throughout the stages of writing their 
graduate paper so as to examine which co-regulation processes can be introduced in a more intensive seminar structure.

\section{Acknowledgements}

We would like to thank the participants in our research. This research was supported by the MOFET Institute: Research, Curriculum and Program Development for Teacher Educators.

\section{References}

Aitchison, C. (2009). Writing groups for doctoral education. Studies in Higher Education, 34, 905-916. http://dx.doi.org/10.1080/03075070902785580

Aitchison, C., \& Guerin, C. (2014). (Eds.). Writing groups for doctoral education and beyond: Innovations in practice and theory, Abingdon: Routledge.

Bansel, P. (2011) Becoming academic: a reflection on doctoral candidacy, Studies in Higher Education, 36, $543-556$. http://dx.doi.org/10.1080/03075079.2011.594592

Beard, C., Clegg, S., \& Smith, K. (2007). Acknowledging the affective in higher education. British Educational Research Journal, 33, 235-252. http://dx.doi.org/10.1080/01411920701208415

Bembenutty, H. (2007). Teachers' self-efficacy and self-regulation. Academic Exchange Quarterly, 11, $155-161$.

Bodrova, E., \& Leong, D.L. (2007). Tools of the Mind: The Vygotskian Approach to Early Childhood Education. Upper Saddle River, NJ: Merrill/Prentice Hall.

Boekaerts M. \& Cascallar, E. (2006). How far have we moved toward the integration of theory and practice in Self-Regulation? Education Psychology Review, 18, 199-210. http://dx.doi.org/10.1007/s10648-006-9013-4

Boekaerts, M., \& Corno, L. (2005). Self-regulation in the classroom: A perspective on assessment and intervention. Applied Psychology, 54, 199-231. http://dx.doi.org/10.1111/j.1464-0597.2005.00205.x

Braun, V., \& Clarke, V. (2006). Using thematic analysis in psychology. Qualitative Research in Psychology, 3, 77-101. http://dx.doi.org/10.1191/1478088706qp063oa

Bruning, R. \& Horn, C. (2000). Developing motivation to write. Educational Psychologist, 35, $25-37$. http://dx.doi.org/10.1207/S15326985EP3501_4

Corno, L. (1995). Comments on Winne: Analytic and systemic researches are both needed. Educational Psychologist, 30, 201-206. http://dx.doi.org/10.1207/s15326985ep3004_5

Delyser, D. (2003). Teaching graduate students to write: a seminar for thesis and dissertation writers. Journal of Geography in Higher Education, 27, 169-181. http://dx.doi.org/10.1080/03098260305676

Drennan, J., \& Clarke, M. (2009). Coursework master's programmes: the student's experience of research and research supervision. Studies in Higher Education, 34, 483-500. http://dx.doi.org/10.1080/03075070802597150

Eisenberg, N. \& Spinrad, T.L. (2004). Emotion-related regulation: Sharpening the definition. Child Development, 75 , 334-339. http://dx.doi.org/10.1111/j.1467-8624.2004.00674.x

Falchikov, N., \& Goldfinch, J. (2000). Student peer assessment in higher education: a meta-analysis comparing peer and teacher marks. Review of Educational Research, 70, 287-322. http://dx.doi.org/10.3102/00346543070003287

Fejes, A., Johansson, K., \& Dahlgren, A. M. (2005). Learning to play the seminar game: students' initial encounters with a basic working form in higher education. Teaching in Higher Education, 10, $29-41$. http://dx.doi.org/10.1080/1356251052000305516

Ferguson, T. (2009). The 'write' skills and more: a thesis writing doctoral students. Journal of Geography in Higher Education, 33, 285-297. http://dx.doi.org/10.1080/03098260902734968

Garcia, T. \& Pintrich P.R. (1994). Regulating motivation and cognition in the classroom: The role of self-schemas and self-regulatory strategies. In D. H. Schunk \& B. J. Zimmerman (Eds.), Self-regulation of learning and performance: Issues and educational applications (pp. 155-179). Hillsdale, NJ: Erlbaum.

Graham, S., \&. Harris, K.H. (2000). The role of self-regulation and transcription skills in writing and writing development. Educational Psychologist, 35, 3-12. http://dx.doi.org/10.1207/S15326985EP3501_2 
Greer, M.L., \& Ross, C. (2013). Senior seminar: across a department and across the years. PRIMUS: Problem, Resources, and Issues in Mathematics Undergraduate Studies, 23, 347-358. http://dx.doi.org/10.1080/10511970.2012.711805

Guerin, C., Kerr, H. \& Green, I. (2015). Supervision pedagogies: narratives from the field. Teaching in Higher Education, 20, 107-118. http://dx.doi.org/10.1080/13562517.2014.957271

Gwet, K. (2012). Handbook of inter-rater reliability ( $3^{\text {rd }}$ ed.). Gaithersburg: Advanced Analytics.

Henderson, R. W. \& Cunningham, L. (1994). Creating interactive sociocultural environment for self-regulated learning. In D. H. Schunk \& B. J. Zimmerman (Eds.), Self-regulation of learning and performance: Issues and educational applications (pp. 255-281). Hillsdale, NJ: Erlbaum.

Hidi, S., \& Boscolo, P. (2006). Motivation and writing. In C.A. MacArthur, S. Graham, \& J. Fitzgerald (Eds.), Handbook of writing research (pp. 144-157). New York: Guilford Press.

Lieberman ,D., Giesbrecht, G.F., \& Muller, U. (2007). Cognitive and emotional aspects of self- regulation in preschoolers. Cognitive development, 22, 511-529. http://dx.doi.org/10.1016/j.cogdev.2007.08.005

Lillis, T., \& Turner. J. (2001). Student writing in higher education: Contemporary confusion, traditional concerns. Teaching in Higher Education, 6, 57-68. http://dx.doi.org/10.1080/13562510020029608

Merrill, B. (2001). Learning and teaching in universities: perspectives from adult learners and lectures. Teaching in Higher Education, 6, 5-17. http://dx.doi.org/10.1080/13562510020029563

Nicol, D. J., \& Macfarlane-Dick, D. (2006). Formative assessment and self-regulated learning: A model and seven principles of good feedback practice. Studies in Higher Education, 31, 199-218. http://dx.doi.org/10.1080/03075070600572090

Nordentoft, H. M., Thomsen, R., \& Wichmann-Hansen, G. (2013). Collective academic supervision: a model for participation and learning in higher education. Higher Education, 65, 581-593. http://dx.doi.org/10.1007/s10734-012-9564-x

Park, C. L., Edmondson, D., \& Lee, J. (2012). Development of self-regulation abilities as predictors of psychological adjustment across the first year of college. Journal of Adult Development, 19, 40-49. http://dx.doi.org/10.1007/s10804-011-9133-z

Peterson, C. H. (2012). The individual regulation component of group emotional intelligence: Measure development and validation. The Journal for Specialists in Group Work, 37, 232-251. http://dx.doi.org/10.1080/01933922.2012.686962

Phillips, T. (2012). Graduate Writing Groups: Shaping Writing and Writers from Student to Scholar, Diversity in the Writing Center, 10. Retrieved from http://www.praxisuwc.com/phillips-101/

Pintrich, P. R. (2000). The role of goal orientation in self-regulation learning. In M. Boekaerts, P. R. Pintrich \& M. Zeidner (Eds.), Handbook of self-regulation: Theory, research and applications. San Diego, CA: Academic Press. http://dx.doi.org/10.1016/B978-012109890-2/50043-3

Pintrich, P. R. (2004). A conceptual framework for assessing motivation and self-regulated learning in college students. Educational Psychology Review, 16, 385-407. http://dx.doi.org/10.1007/s10648-004-0006-x

Sanz de Acedo Lizarraga, M. L., Sanz de Acedo Baquedano, M. T., Goicoa Mangado, T., \& Cardelle-Elawar, M. (2009). Enhancement of thinking skills: Effects of two intervention method. Thinking Skills and Creativity, 4, 30-43. http://dx.doi.org/10.1016/j.tsc.2008.12.001

Schunk, D. H., \& Ertmer, P. (2000). Self-regulation and academic learning: self-efficacy enhancing. In M. Boekaerts, Pintrich, P. R., \& Zeidner, M. (Eds.). Handbook of self-regulation. (pp. 631-649). San Diego: Academic Press. http://dx.doi.org/10.1016/B978-012109890-2/50048-2

Schunk, D. H., \& Pajares, P. (2005). Competence perception and academic functioning. In A.J Elliot \& C. S. Deweck (Eds.) Handbook of Competence and Motivation (pp. 85-104). New York: Guildford Press.

Schunk, D. H., \& Zimmerman, B. J. (Eds.) (2007a). Motivation and self-regulated learning: Theory, research, and applications. Mahwah, NJ: Erlbaum.

Schunk, D.H., Zimmerman, B. J. (2007b). Influencing children's self-efficacy and self-regulation of reading and writing through modeling. Reading \& Writing Quarterly, 23, 7-25. http://dx.doi.org/10.1080/10573560600837578 
Semeijn, J.H., Semeijn, J., \& Geldeman, K. J. (2009). Master thesis supervision. Advances in Business Education and Training, 2, 211-222. http://dx.doi.org/10.1007/978-90-481-2973-7_14

Shepard, A.L. (2000). The role of assessment in a learning culture. Educational Researcher, 29, 4-14. http://dx.doi.org/10.3102/0013189X029007004

Struyven, K., Dochy, F. J., \& Janssens, S. (2003). Students' perceptions about new modes of assessment in higher education: a review. In M. Seger, F. Dochy, \& E. Cascallar (Eds.). Optimizing new modes of assessment: in search of qualities and standards, (pp. 171-223), Dordrecht: Klumer. http://dx.doi.org/10.1007/0-306-48125-1_8

Sullivan, L. E., \& Ogloff, J. R. P. (1998). Appropriate supervisor-graduate student relationships. Ethics \& Behavior, 8, 229-248. http://dx.doi.org/10.1207/s15327019eb0803_4

Topping, K. (2003). Self and peer assessment in school and university: reliability, validity and utility, In M. Seger, F. Dochy, \& E. Cascallar (Eds.). Optimizing new modes of assessment in search of qualities and standards (pp. 55-87), Dordrecht: Kluwer. http://dx.doi.org/10.1007/0-306-48125-1_4

Volet, S., Summers, M., \& Thurman, J. (2009). High-level co-regulation in collaborative learning: How does it emerge and how is it sustained? Learning and Instruction, 19, 128-143. http://dx.doi.org/10.1016/j.learninstruc.2008.03.001

Wolters, C. (1998). Self-regulated learning and college students' regulation of motivation. Journal of Educational Psychology, 90, 224-235. http://psycnet.apa.org/doi/10.1037/0022-0663.90.2.224

Ylijoki, O-H. (2001). Master's thesis writing from a narrative approach. Studies in Higher Education, 26, 21-34. http://dx.doi.org/10.1080/03075070020030698

Zimmerman, B. J. (2000). Attaining self-regulation: A social cognitive perspective. In M. Boekaerts, P. R. Pintrich \& M. Zeidner (Eds.). Handbook of Self-Regulation: Theory, Research and Applications (pp. 13-39). San Diego, CA: Academic Press. http://dx.doi.org/10.1016/B978-012109890-2/50031-7

Zimmerman, B. J. (2002). Achieving self-regulation: The trial and triumph of adolescence. In F. Pajaers \& T. Urdan (Eds.), Adolescence and education: Vol. 2, Academic motivation of adolescents (pp. 1-27). Greenwich, CT: Information Age.

Zimmerman, B. J. (2008). Investigating self-regulation and motivation: Historical background, methodological developments, and future prospects. American Educational Research Journal, 45, 166-183. http://dx.doi.org/10.3102/0002831207312909

Zimmerman, B. J., \& Schunk, D. H. (2008). Motivation an essential dimension of self-regulated learning. In D.H. Schunk, \& B.J. Zimmerman (Eds.). Motivation and self-regulated learning: theory, research, and applications (pp. 1-30). NY: Taylor \& Francis Group. 


\section{Appendix 1: Reflective Questionnaire}

What are the main topics you learned today?

What are your feelings regarding your class experience today?

Do you have any questions about what you learned?

Do you have any requests?

Do you have any recommendations?

\section{Appendix 2: Perception Questionnaire}

Part 1

1) What are the most important things you learned in this lesson?

2) Please write any questions that you feel still need to be answered.

Part 2

1) Describe your situation before the seminar regarding the following items:

- Progress in writing your research proposal

- Your connection with your advisor

- Emotionally (self-confidence, self-efficacy, feeling good/bad/other)

- Other

2) Describe your condition now, post the workshop regarding:

- Progress in writing your research proposal

- Your connection with your advisor

- Emotionally (self-confidence, self-efficacy, feeling good/bad/other)

- Other

3) What did the workshop classes contribute to you?

4) Do you have any remarks or recommendations for future seminars? Please write in detail and provide examples. 